\title{
Bubbles in Insulating Liquids: A Short Review
}

\author{
Michael G. Danikas \\ Department of Electrical \& Computer Engineering \\ Democritus University of Thrace, Greece \\ mdanikas@ee.duth.gr
}

\begin{abstract}
This paper deals with the influence of bubbles in insulating liquids (e.g. transformer oil) and their role in liquid breakdown. Bubbles play a deleterious role in the dielectric strength of insulating liquids. Depending on their shape and localized electric field, bubbles may significantly lower the dielectric strength of an insulating liquid. The present paper offers a short review -albeit incomplete- on the role of bubbles and tries to elucidate their relation to the total breakdown of dielectric liquids. It also proposes some further fields of research.
\end{abstract}

Keywords-bubbles; insulating liquids; low refractive index; dielectric strength; breakdown strength; bubbles; streamer

\section{INTRODUCTION}

Insulating liquids are widely used in high voltage equipment to easily fill a space needed to be insulated and since they can be circulated easily, they can also be used to dissipate any heat generated in the system. They exhibit, in general, a satisfactory dielectric strength [1]. Their principal disadvantage is that they can be easily contaminated. Of the various insulating liquids, transformer oil is the most widely used. Previous research has investigated the physics of the breakdown mechanism in insulating liquids in detail [2-5]. Statistical investigations have also been conducted and various statistical models have been proposed in $[6,7]$. A special subject of interest when working with insulating liquids is the subject of bubbles, the presence of which may vastly increase the probability of breakdown. It is the aim of the present paper to approach the subject of bubbles in insulating liquids and to try to give an overall picture of the work done. Needless to say that the present review is incomplete in terms of investigating the numerous factors affecting the dielectric strength of insulating liquids, as it is only focused in the effect of bubbles.

\section{BUBBLES IN INSULATING LIQUIDS}

The gas content of an insulating liquid is one of the most important factors affecting the conduction and breakdown processes. The gas can be traced either in solution or in suspension in the form of bubbles. The dielectric strength of a dielectric liquid is often no more than that of a gas at moderate pressure (5 to $10 \mathrm{bar}$ ), even though the density of the former is 100 time greater [8]. Pohl studying the motion of suspensoids in divergent electric fields, made the clear distinction between dielectrophoresis (arising due to the tendency of conducting particles to become polarized and move into regions of highest field strength) and electrophoresis (arising from the electrostatic attraction of charged electrodes for charged particles) [9]. Years later, the same researcher gave experimental evidence according to which the phenomenon of dielectrophoresis becomes large and noticeable when large suspensoids are subjected to non-uniform fields [10].

Considering the field strength inside a spherical bubble Kao calculated the change in stored energy due to the presence of the bubble in [11]. Then, assuming that a spherical bubble may deform into a spheroidal shape, he calculated the change in stored energy. The difference between these two illustrates the energy for the bubble deformation. It is obvious that if this difference is positive, a spherical bubble will elongate in the direction of the field. However, despite his elaborate analysis, Kao did not present any experimental data to support his theoretical calculations. Later on, the same researcher experimenting with air bubbles and water drops in transformer oil and reached two interesting conclusions: (a) that gas bubbles and liquid drops tend to elongate in the direction of the applied field in a fluid dielectric, irrespective of whether the permittivity of the bubble (or drop) is larger or smaller than that of the surrounding liquid, and (b) that the greater the difference in permittivity between the bubble (or drop) and the liquid dielectric and the larger the original size of the bubble (or drop), the smaller the electric field required to cause elongation [12]. Although Kao's work was criticized in [13] because of his criteria for energy relations, the latter also suggested that a gas bubble in a liquid, subjected to an electric field between parallel plane electrodes, assumes the shape of a prolate spheroid in the direction of the electric field, elongating until a critical shape is reached when the bubble becomes unstable. In a later publication, Kao proposed that near breakdown there is only one filament in which the current density is large enough to cause vaporization of the liquid and consequently bubbles [14]. Experimental data presented in [13] indicated that a conducting or a non-conducting bubble for which its permittivity is 20 times larger than the permittivity of the liquid, has a critical stable shape corresponding to a critical value of the ratio of the major to the minor semi-axis of the bubble. At low values of the above mentioned ratio, however, elongation requires much higher fields, although not greater than the required for breakdown in pure liquids.

In a work reminiscent of the research done by Pohl [9, 10], Stuetzer performed studies by analyzing the flow of a bubblecontaining charged liquid in a rectangular channel, and drew the conclusion that gas bubbles in charged regions of an insulating liquid move away from high fields. They do not 
acquire a net charge of their own but they are moved by electrical pressure gradients and polarization forces. The bubble motion is determined by electrical pressure gradients, superimposed on hydraulic pressure distribution and by dielectrophoretic forces [15]. A somehow complete picture of the behavior of a gas bubble in a liquid dielectric was given in [8], where an approximate condition for bubble stability was proposed, assuming that (a) a gas bubble has the shape of a hollow prolate ellipsoid the major axis of which is parallel to the applied electric field, (b) the field inside the bubble is uniform and very nearly equal to the applied electrical field, (c) the field outside (i.e. in the liquid) is nowhere larger than the field inside the bubble and (d) the pressure in the gas bubble is larger than the pressure in the liquid outside the stressed region. Of the four main possible sequences (1-elongation/ignition/ instability/breakup, 2-no elongation/ignition/instability/breakup 3-no elongation/ignition/no instability, 4-elongation/without ignition), Felici considered the sequences 3 and 4 rather rare. In fact, after ignition, strong instability and breakup of the bubble is likely to occur; very high field concentrations may develop and cause intrinsic breakdown of the liquid phase. Gas bubble behavior was also the subject of [16], where it was shown that an electrically stressed bubble volume decreased by more than an order of magnitude in the naphthenic mineral oil, by over $50 \%$ in the blend of a naphthenic and a paraffinic oil (NH-PH) but it increased by 4 to 1 in the paraffinic mineral oil. Such differences are possibly due to the gas-evolving properties of the paraffinic mineral oil. In [16], it was also indicated that various discharges related to an electrically stressed gas bubble were observed ranging over a 10 to 1 magnitude. This is because at times the whole bubble may discharge or just parts of it. Obviously, the largest partial discharge magnitudes are related to the complete bubble volume. The observations of [16] were not at variance with those of [17], even though the latter used a completely different experimental setup.

Going back to older research, it was indicated quite early that bubbles are associated with the breakdown of insulating liquids, with bubbles on the electrode surfaces having a most important role [18]. In [18], it was pointed out that the main effect of bubbles is to cause enhanced emission of electrons from the underlying metal due to the local increase of the electric field. Other researchers also associated the breakdown mechanism with the development of gas bubbles in an insulating liquid $[19,20]$. Bubble breakdown in liquids was also discussed in more recent publications, where it was stressed that bubbles may be formed because of (i) gas pockets on the surface of the electrodes, (ii) due to irregularities of electrode surfaces, where point charge concentrations may lead to corona discharge and thus vaporization of the liquid, (iii) changes in pressure and temperature, and (iv) dissociation of products by electron collisions giving rise to gaseous products $[21,22]$. Such ideas are intimately linked with earlier theories about breakdown in insulating liquids, namely that in $[23,24]$ which observed a strong dependence of the dielectric strength on pressure. Since the dielectric strength increases with pressure, they suggested that such pressure dependence indicates that there is a change of phase (i.e. formation of a bubble) during some step in the breakdown process. A bubble may expand until it reaches a critical length or until it bridges the gap. They proposed a model according to which the local energy input equals the heat required to raise the temperature of $\mathrm{m}$ grams of liquid from ambient temperature to the boiling temperature and vaporize it. Such a model shows a strong pressure dependence of the dielectric strength. The same authors in a later publication, however, although supporting the idea of a breakdown occurring in the gas phase, did not exclude the possibility of an electronic multiplication process taking place at elevated temperatures [25].

The instability of a bubble can either result in the continuous elongation of the bubble until it bridges the gap between the electrodes or there may well be some sharp points at the edges of the bubble which will result in its disintegration. Such disintegration may also result in a total breakdown of the liquid [26]. Bubble instability was studied in relation to streamer development in [27], where it was shown that the bubble can take different shapes, with the local electric field at the liquid-bubble interface having very high values. The work in $[26,27]$ is original in that it relates bubbles with streamer development and it is reminiscent of earlier work reported in $[8,13]$. Relatively recently, some researchers proposed a critical field value necessary to form a critical sized bubble [28]. The bubble is formed at the tip of an electrode as soon as the field is greater than this critical value [28]. Such an approach helps in distinguishing between various insulating oils regarding the respective critical bubble formation fields, and consequently the respective dielectric strengths. The observation made in [29] that in highly divergent fields, breakdown is preceded by the formation of a region of very low refractive index at the cathode seems to support the thoughts in [28]. It has to be noted, however, that such a low refractive index region was attributed by some to a gas phase composed of microbubbles in the liquid [30-33] and by others to a plasma raising the temperature of the liquid [2].

The effect of pressure on bubble behavior in insulating liquids was early noticed in $[34,35]$, where it was pointed out that the dependence of dielectric strength on hydrostatic pressure implies that breakdown takes place in the gaseous phase. Pressure effects disappear when the applied field rate of voltage rise is greater than $4 \mathrm{MV} / \mathrm{cm} / \mu \mathrm{sec}$, indicating that the bubble mechanism may not be operative beyond a certain value of rate rise [36]. A combination of the reported theories between [2] and [30-33] was tried in [37], where it was proposed that although the initial stage of breakdown in transformer oil is due to a gas bubble formed by vaporization of liquid by local heating in a strong field region of the electrode surface, during breakdown a plasma channel will be formed with a high initial resistance. Such initial resistance changes from a few ohms to a few hundreds milliohms due to Joule heating caused by the arc current flowing through the arc channel. Pressure effects on bubble were analyzed in [38], where it was noted that a vapor bubble can be formed when a liquid is subjected to a highly localized heat pulse that rapidly raises the temperature of the liquid. The authors of [38] proposed that an increase in hydrostatic pressure decreases the maximum radius of a bubble by a certain factor derived from the value of the pressure far away from the bubble. They also remarked that there is no significant bubble expansion over 1 $\mathrm{MPa}$. For slightly viscous liquids, the bigger the maximum 
bubble radius, the more violent is its collapse and, consequently, the higher the pressure wave amplitude emitted through the liquid and the higher the dissipated energy of the bubble [39].

Viscosity is an important parameter in shaping the behavior of a bubble, although it is not the only one. Moreover, as was reported in [40], the prediction of the deformed bubble shape is difficult since the stress distribution on its surface depends on localized field distribution. This is a general conclusion applied to gas bubbles, although the research in [40] was referring to a different type of bubbles from those investigated here. Space charge, developed on the bubble surface, is of crucial importance determining the bubble behavior. The involvement of multiple parameters in calculating the space charge as well as the uncertainty of determining accurately the value of the applied electric field makes the calculation of space charge difficult [41]. In [42], some researchers attacked the problem of bubbles from another viewpoint, namely that of the different gases. They indicated that transformer oil having sulfur hexafluoride instead of air gives higher breakdown values and this disregarding chemical purity and humidity. This has to be expected given the electronegativity of the sulfur hexafluoride. In [43], it was indicated that a gas bubble may elongate and, in case of very high local field, charge can be injected into the liquid near the poles of the bubble. In case of a string of bubbles in the liquid, a breakdown in one bubble may lead to an increase of the field in the nearby bubbles, increasing thus the probability of a total breakdown. Furthermore, instability in a gas bubble is a pre-condition for possible paths for initiation of streamers. The aforementioned work reminds of earlier research regarding bubble behavior [8]. The string of bubbles reminds also of similar phenomena in solid dielectrics, where a partial discharge in an enclosed cavity may trigger partial discharges in nearby cavities [44-46]. Such parallels between liquid insulation and solid dielectrics [43-46] may point out to some common ground among the breakdown (or prebreakdown) phenomena in liquid dielectrics and solid insulating materials.

Besides pressure, temperature is also a factor to be reckoned with when we refer to bubbles in insulating liquids. An insulating liquid presents a reduced surface tension at elevated temperatures. Consequently, a reduced surface tension will result in a reduction of pressure inside the bubble. Thus, the electric field needed for the ignition of a bubble at elevated temperature will be less and initiation of breakdown may result [47, 48]. Investigating composite (solid/liquid) insulating systems at both ambient and elevated temperatures, it was reported that a bubble -under some special circumstancesmay burst by a partial discharge and partially dissolve in the liquid $[48,49]$. This of course depends on the nature of the insulating liquid $[16,48,50,51]$. However, and despite the fact that in some insulating liquids bubbles may disperse because of the partial discharges, it is still unclear the sort of damage such discharges may cause in the solid insulation. It must, however, be noted that the temperature effect is a complex phenomenon because of the possible changes in cathode emission, gas content and liquid viscosity [52].
As was pointed out in early papers [53], factors such as pressure and temperature affect bubble behavior. Such effects may differ depending on the use of AC or DC voltages and also on whether the applied field is uniform or non-uniform. The research reported in [53] is reminiscent of earlier research, where it was suggested that with non-uniform field configurations, the initiation of breakdown can be divided into two parts: one including the formation of gas bubbles in the liquid at the cathode and the other being an adequate multiplication by a gaseous ionization in the bulk of the liquid [54]. Relatively recent research [55] distinguished between the mechanisms of Townsend and streamer in bubbles in liquids, considering some limiting cases regarding bubble dimensions and the minimum duration of applied field. The authors admitted, however, that such mechanisms are expressions of a more complex breakdown process phenomenon depending on both the duration of the applied field and the diameter of the bubble. The authors in [55] distinguish the aforementioned mechanisms in liquids, whereas most of other researchers pay attention mainly to the steamer mechanism [5, 56]. Bubble conductivity as a factor was investigated in [57], where it was shown that for non-conductive bubbles the instability takes place with formation slender waist whereas with conductive bubbles the instability takes place at the tips of the bubble.

The question of a bridge formed from bubbles in transformer oil under non-uniform electric fields was discussed in [58]. The authors showed that bridges can be formed from bubbles and consequently facilitate the final failure of the liquid. Paper [58] elucidates some aspects of the breakdown in liquids and brings into the fore the question of the influence of electrode configuration [59] as well that of the effect of the oil flow velocity upon the breakdown strength [7, 52, 60, 61]. Despite the fact that oil flow velocity refers more to particle removal from the liquid, [58] brings about a discussion as to the removal of bubbles. The question of bubble bridges was the subject of [62], where it was remarked that bubble bridges are more likely to affect the breakdown voltage in uniform electrode arrangements than in non-uniform electrode arrangements. Similar observations, albeit in a different context, were also made in $[48,50,51]$.

\section{THOUGHTS ABOUT FUTURE RESEARCH}

It is evident from the above that a considerable amount of work has been done on bubbles in insulating liquids during the past decades. Models of bubble behavior have been proposed as well as experimental data have been presented. There is an intimate link between bubbles and liquid breakdown, although bubbles are not the sole cause of liquid breakdown. Bubbles play a vital role both in conventional insulating liquids and also in liquids for superconducting applications [63-65]. Although there are two main groups of theories put forward to explain electrical breakdown in dielectric liquids (i.e. (a) those which suggest that breakdown takes place in a gas or vapor phase before complete collapse occurs, and (b) those which propose an electron avalanche in the liquid which grows to a critical size $[23,24,4,66-70])$, it would be interesting if we can explore the possibility of the two groups of theories to be intimately linked. In the past, significant amount of research has been performed on mineral oils with additives [71]. In [71], 
it was remarked that bubbles formed at lower stresses in a gassaturated liquid are likely to be expelled from the high field regions before the right conditions for a gaseous discharge arise. It would be highly interesting if further work can be done in this direction regarding bubbles, additives and -the recent trend of research-vegetable oils [72].

Strings of bubbles have been researched in [43, 73] and a possible parallel was drawn above between this research and work done in solid dielectrics [44-46]. It would be challenging to see whether such micro-bubble interaction and behavior is also valid for vegetable oils. Liquid flow and its effect upon the dissolution of bubbles is a subject needing further work. It is already known that circulating an insulating liquid offers higher breakdown strength than a stationary oil [7, 30, 60]. It is, however, questionable whether such a liquid flow effect is due simply to the liquid flow velocity or whether other parameters, such as liquid viscosity, liquid density and surface tension play an equally important role. It was also observed that the breakdown strength of a liquid cannot be raised indefinitely by increasing the liquid flow velocity because of turbulent flow and, consequently, cavitation $[60,74]$. Liquid flow velocity and the upper limits of it, as well as the aforementioned proposals, can be researched in the future, especially with regards to the advent of nanofluids [75].

\section{CONCLUSIONS}

In the context of the present paper, some aspects of bubbles in insulating liquids were studied. This short review traces some important research with regard to insulating fluids back in the thirties of the last century. It points out that some problems regarding bubbles and their deteriorating role for liquid insulation stay with us even nowadays. Bubble behavior depends on bubble shape, liquid permittivity, liquid viscosity, liquid density, applied electric field and localized electric field, among others. Although significant steps were taken in elucidating various aspects of bubble behavior in conventional insulating liquids, a lot remains to be done with the advent of a new class of liquids, such as the nanofluids.

\section{REFERENCES}

[1] D. F. Binns, "Breakdown in liquids", in: Electrical Insulation, Peter Peregrinus Ltd., London, UK, 1983

[2] R. N. Allan, E. M. Hizal, "Prebreakdown phenomena in transformer oil subjected to non-uniform fields", Proceedings of the IEE, Vol. 121, pp. 227-231, 1974

[3] W. G. Chadband, J. H. Carderwood, "The propagation of discharges in dielectric liquids", Journal of Electrostatics, Vol. 7, pp. 75-91, 1979

[4] A. H. Sharbough, J. C. Devins, S. J. Rzad, "Progress in the field of electric breakdown in dielectric liquids", IEEE Transactions on Electrical Insulation, Vol. 13, pp. 249-276, 1978

[5] A. Beroual, M. Zahn, R. Badent, K. Kist, A. J. Schwab, H. Yamashita, K. Yamazawa, M. Danikas, W. G. Chadband, Y. Torshin, "Propagation and structure of streamers in liquid dielectrics", IEEE Electrical Insulation Magazine, Vol. 14, No. 2, pp. 6-17, 1998

[6] B. Epstein, "Statistical aspects of fracture problems", Journal of Applied Physics, Vol. 19, pp. 140-147, 1948

[7] W. R. Bell, "Influence of specimen size on the dielectric strength of transformer oil", IEEE Transactions on Electrical Insulation, Vol. 12, No. 4, pp. 281-292, 1977
[8] N. J. Felici, "Bubbles, partial discharges and liquid breakdown", Electrostatics, Vol. 79, Institute of Physics Conference Series Vol. 48, pp. 181-190, 1979

[9] H. Pohl, "The motion and precipitation of suspensoids in divergent electric fields", Journal of Applied Physics, Vol. 22, No. 7, pp. 869-871, 1951

[10] H. Pohl, "Some effects of non-uniform fields on dielectrics", Journal of Applied Physics, Vol. 29, No. 8, pp. 1182-1188, 1958

[11] K. C. Kao, "Some electromechanical effects on dielectrics", British Journal of Applied Physics, Vol. 12, pp. 629-632, 1961

[12] K. C. Kao, "Deformation of gas bubbles and liquid drops in an electrically stressed insulating liquid", Nature, Vol. 208, pp. 1279-280, 1965

[13] C. G. Garton, Z. Krasucki, "Bubbles in insulating liquids: Stability in an electric field", Proceedings of the Royal Society, Vol. 280, pp. 211-226, 1964

[14] K. C. Kao, "Theory of high-field electric conduction and breakdown in dielectric liquids", IEEE Transactions on Electrical Insulation, Vol. 11, No. 4, pp. 121-128, 1976

[15] O. M. Stuetzer, "Gas bubbles in a charged liquid", Journal of Applied Physics, Vol. 34, No. 4 (Pt. 1), pp. 958-963, 1963

[16] R. T. Harrold, "The behavior of electrically stressed gas bubbles trapped within naphthenic and paraffinic mineral oils", IEEE Power Engineering Society Summer Meeting, Vancouver, pp. 1-5, 1979

[17] R. Meyrueix, P. Atten, R. Tobazeon, "On the behavior of a plane gaseous cavity in an insulating liquid subjected to an AC voltage", IEEE Transactions on Electrical Insulation, Vol. 18, No. 1, pp. 65-77, 1983

[18] R. Hancox, H. Tropper, "The breakdown of transformer oil under impulse voltages", Proceedings of the IEE, Part A: Power Engineering, Vol. 105, No. 21, pp. 250-262, 1958

[19] J. L. Maksiejewski, H. Tropper, "Some factors affecting the measurement of the electric strength of organic liquids", Proceedings of the IEE, Part II: Power Engineering, Vol. 101, No. 80, pp. 183-190, 1954

[20] P. Gazzana-Priaroggia, G. Palandri, "The influence on the oil dielectric strength of the gas pressure in equilibrium with the oil", Journal of the Electrochemical Society, Vol. 107, No. 11, pp. 884-886, 1960

[21] M. S. Naidu, V. Kamaraju, High Voltage Engineering, Tata McGraw-Hill Publishing Company Limited, New Delhi, 2000

[22] C. L. Wadhwa, High Voltage Engineering, New Age International (P) Limited, New Delhi, 2001

[23] P. K. Watson, A. H. Sharbaugh, "High-field conduction currents in liquid n-hexane under microsecond pulse conditions", Journal of Electrochemical Society, Vol. 107, No. 6, pp. 516-521, 1960

[24] A. H. Sharbaugh, P. K. Watson, Conduction and breakdown in liquid dielectrics, Progress in Dielectrics, Vol. 4, Academic Press Inc., New York, NY, USA, 1962

[25] A. H. Sharbaugh, P. K. Watson, "The electric strength of hexane vapor and liquid in the critical region", Journal of Applied Physics, Vol. 48, No. 3, pp. 943- 950, 1977

[26] A. Beroual, "Behavior of charged and uncharged bubbles in dielectric liquids subjected to electric stress", Journal of Applied Physics, Vol. 71, No. 3, pp. 1142-1145, 1992

[27] T. Aka-Ngnui, A. Beroual, "Bubble dynamics and transition into streamers in liquid dielectrics under a high divergent electric field", Journal of Physics D: Applied Physics, Vol. 34, pp. 1408-1412, 2001

[28] I. Timoshkin, S. MacGregor, M. M. Given, V. Atrazhev, V. Vorobev, "Critical parameters of gas cavities in dielectric liquids stressed with high electric fields", Acta Physica Polonica A, Vol. 115, No. 5, pp. 1022-1024, 2009

[29] B. Farazmand, "Study of electric breakdown of liquid dielectrics using Schlieren optical techniques", British Journal of Applied Physics, Vol. 12, No. 5, pp. 251-254, 1961

[30] J. K. Nelson, P. B. McGrath, "Evidence for transitions in the prebreakdown mechanism of liquid dielectrics", Proceedings of the IEE, Vol. 122, No. 12, pp. 1439-1442, 1975 
[31] E. O. Forster, P. Wong, "High speed laser Schlieren studies of electrical breakdown in liquid hydrocarbons", IEEE Transactions on Electrical Insulation, Vol. 12, No. 6, pp. 435-442, 1977

[32] E. O. Forster, "Research in the dynamics of electrical breakdown in liquid dielectrics", IEEE Transactions on Electrical Insulation, Vol. 15, No. 3, pp. 182- 185, 1980

[33] S. Sakamoto, H. Yamada, "Optical study of conduction and breakdown in dielectric liquids", IEEE Transactions on Electrical Insulation, Vol. 15 , No. 3, pp. 171-181, 1980

[34] F. M. Clark, "The role of dissolved gases in determining the behavior of mineral insulating oils", Journal of the Franklin Institute, Vol. 215, No. 1, pp. 39-67, 1933

[35] H. Tropper, "The effect of dissolved gases on the electrical conduction and breakdown of insulating oil", Journal of Electrochemical Society, Vol. 108, No. 2, pp. 144-150, 1961

[36] K. C. Kao, J. P. C. McMath, "Time-dependent pressure effect in liquid dielectrics", IEEE Transactions on Electrical Insulation, Vol. 5, No. 3 pp. 64-68, 1970

[37] J. Kudelcik, M. Gutten, "Measurement of electrical parameters of breakdown in transformer oil", Proceedings of the MEASUREMENT 7th International Conference, pp. 393-396, Smolenice, Slovakia, May 20-23, 2009

[38] H. Frid, M. Becerra, "Simulation of microbubbles during the initial stages of breakdown in cyclohexane", 2013 Annual Report on Conference on Electrical Insulation and Dielectric Phenomena, Shenzhen, China, October 20-23, 2013

[39] F. Jomni, F. Aitken, A. Denat, "Dynamics of microscopic bubbles generated by a corona discharge in insulating liquids: Influence of pressure", Journal of Electrostatics, Vol. 47, pp. 49-59, 1999

[40] J. S. Eow, M. Ghadiri, A. Sharif, "Deformation and break-up of aqueous drops in dielectric liquids in high electric fields", Journal of Electrostatics, Vol. 51-52, pp. 463-469, 2001

[41] M. Talaat, A. El-Zein, "Analysis of air bubble deformation subjected to uniform electric field in liquid dielectric", International Journal of Electromagnetics and Applications, Vol. 2, No. 1, pp. 4-10, 2012

[42] A. S. Tyuftyaev, M. Kh. Gadzhiev, M. A. Sargsyan, P. L. Akimov, N. A. Demirov, "The effect of gas bubbles on electrical breakdown in transformer oil", Journal of Physics: Conference Series, Vol. 774, 2016

[43] D. A. Medvedev, A. L. Kupershtokh, A. A. Bukovets, "Dynamics of bubble in dielectric liquid in electric field: Mesoscopic simulation", Proceedings of the $19^{\text {th }}$ IEEE International Conference on Dielectric Liquids (ICDL), Manchester, UK, 25-29 June, 2017

[44] D. P. Agoris, N. D. Hatziargyriou, "Approach to partial discharges development in closely coupled cavities embedded in solid dielectrics by the lamped capacitance model", IEE Proceedings-A, Vol. 140, No. 2, pp. 131-134, 1993

[45] D. P. Agoris, N. D. Hatziargyriou, "A modelistic consideration of the interaction between discharges in cavities of solid dielectrics", Proceedings of the $8^{\text {th }}$ International Symposium in High Voltage Engineering (ISH), Yokohama, Japan, August 23-27, 1993

[46] M. G. Danikas, "Partial discharge behavior of two (or more) adjacent cavities in polyethylene samples", Journal of Electrical Engineering, Vol. 52, No. 1-2, pp. 36-39, 2001

[47] K. C. Kao, J. B. Higham, "The effects of hydrostatic pressure, temperature and voltage duration on the electric strengths of hydrocarbon liquids", Journal of Electrochemical Society, Vol. 108, No. 6, pp. 522-528, 1961

[48] M. G. Danikas, A study of the behavior of a uniaxially orientated polyethylene tape/oil insulating system subjected to electrical and thermal stresses, Ph.D. Thesis, University of London, Queen Mary College, Department of Electrical and Electronic Engineering, 1985

[49] T. Bertula, V. Palva, E. Talvio, "Partial discharge measurement on oilpaper insulated transformers", CIGRE REPORT, Paper 12-07, pp. 1-12, 1968

[50] A. J. Pearmain, M. G. Danikas, "A study of the behavior of a uniaxially oriented polyethylene tape/oil insulating system subjected to electrical and thermal stresses", IEEE Transactions on Electrical Insulation, Vol. 22, No. 4, pp. 373- 382, 1987

[51] M. G. Danikas, "Study of samples of a composite insulating system under electrical and thermal stresses", IEEE Electrical Insulation Magazine, Vol. 6, No. 1, pp. 18-23, 1990

[52] [52] M. G. Danikas, Factors affecting the breakdown strength of transformer oil, M. Sc. Thesis, University of Newcastle-upon-Tyne, Faculty of Engineering, Department of Electrical and Electronic Engineering, 1982

[53] S. Ogata, T. Yoshida, H. Shinohara, "Small air bubble formation in insulating liquids under strong non-uniform electric field", Japanese Journal of Applied Physics, Vol. 18, No. 2, pp. 411-412, 1979

[54] M. E. Zein El-Dine, H. Tropper, "The electric strength of transformer oil", Proceedings of the IEE, Vol. 103, Pt. C, pp. 35-45, 1956

[55] V. M. Atrazhev, V. S. Vorobev, I. V. Timoshkin, S. J. MacGregor, M. J. Given, M. P. Wilson, T. Wang, "Breakdown processes in gas microbubbles in liquids under electric stress", IEEE Transactions on Dielectrics and Electrical Insulation, Vol. 19, No. 5, pp. 1552-1558, 2012

[56] R. Badent, Modell der elektronendominanten Streamerentladung in Isolieroel, Ph. D. Thesis, Universitaet Karlsruhe, Institut fuer Elektroenergiesysteme und Hochspannungstechnik (IEH), 1996

[57] H. Du, S. Pancheshnyi, A. Krivda, "Deformation of air and water bubbles in mineral oil under electric field", Proceedings of $22^{\text {nc }}$ International Symposium on Plasma Chemistry, Antwerp, Belgium, July 5-10, 2015,

[58] D. Cai, L. Liu, G.-X. Cheng, Q. Zhang, X.-L. Zhao, Q. Zhao, "Bubble motion in transformer oil under non-uniform electric fields", Chinese Physics Letters, Vol. 30, No. 3, pp. 037701/1 - 037701/5, 2013

[59] W. R. Wilson, A. L. Streater, E. J. Tuohy, "Application of volume theory of dielectric strength of oil circuit breakers", Transactions of the AIEE, Vol. 74, pp. 677-688, 1955

[60] M. G. Danikas, "Breakdown of transformer oil", IEEE Electrical Insulation, Vol. 6, No. 5, pp. 27-34, 1990

[61] J. D. Cross, "Breakdown across a dielectric spacer in insulating oil and the role of electrodynamics in liquid breakdown", IEEE Transactions on Electrical Insulation, Vol. 17, No. 6, pp. 493-498, 1982

[62] C. Qin, Y. He, B. Shi, T. Zhao, F. Lv, X. Cheng, "Experimental study on breakdown characteristics of transformer oil influence by bubbles", Energies, Vol. 11, pp. 1-11, 2018

[63] J. Gerhold, "Dielectric breakdown of cryogenic gases and liquids", Cryogenics, Vol. 19, No. 10, pp. 571-584, 1979

[64] M. Blaz, M. Kurrat, "Studies of breakdowns in liquid nitrogen at different pressures between Rogowski electrodes”, Physics Procedia, Vol. 36, pp. 1330- 1336, 2012

[65] S. Fink, H. R. Kim, R. Mueller, M. Noe, V. Zwecker, "AC breakdown voltage of liquid nitrogen depending on gas bubbles and pressure", Proceedings of the 2014 International Conference on High Voltage Engineering and Application, Poznan, Poland, September 8-11, 2014

[66] A. von Hippel, "Electric breakdown of solid and liquid insulators", Journal of Applied Physics, Vol. 8, pp. 815-832, 1937

[67] T. W. Dakin, D. Berg, "Luminous spots on electrodes in insulating oil gaps", Nature, Vol. 184, p. 120, 1959

[68] I. Adamczewski, Ionization, conductivity and breakdown in dielectric liquids, Taylor \& Francis, London, UK, 1969

[69] T. J. Lewis, "Molecular structure and the electrical strength of liquid hydrocarbons", Journal of Electrochemical Society, Vol. 107, pp. 185191,1960

[70] A. Mukhtaruddin, M. Isa, M. Mohd Noor, M. Rafi Adzman, B. Ismail M. N. K. H. Rohani, M. F. Ain, "Simulation of conditions affecting partial discharge partial discharge initiation in microbubble immersed in dielectric liquid", Jurnal Teknologi (Sciences \& Engineering), Vol. 80, No. 6, pp. 69-75, 2018

[71] A. A. Zaky, I. Y. Megahed, C. Evangelou, "The effect of organic additives on the breakdown and gassing properties of mineral oils", Journal of Physics D: Applied Physics, Vol. 9, pp. 841-850, 1976 
[72] S. Islam, Md. Selim Hossain, Md. Farhamdur Reza, Md. Mamunur Rashid, "Experimental investigation of insulating properties of vegetable oil under high voltage", European Journal of Engineering Research and Science, Vol. 4, No. 1, pp. 17-23, 2019

[73] N. Yu Babaeva, D. V. Tereshonok, G. V. Naidis, B. M. Smirnov, "Initiation of breakdown in strings of bubbles immersed in transformer oil and water: string orientation and proximity of bubbles", Journal of Physics D: Applied Physics, Vol. 49, 2016

[74] J. K. Nelson, B. Salvage, W. Sharpley, "Electric strength of transformer oil for large electrode areas", Proceedings of the IEE, Vol. 118, pp. 388393, 1971

[75] M. G. Danikas, "Breakdown in nanofluids: A short review on experimental results and related mechanisms", Engineering, Technology \& Applied Science Research, Vol. 8, No. 5, pp. 3300-3309, 2018 